TRANS $\cdot$ núm. I7 $\cdot 2013$

NOTA $\cdot 195-201$
El Renacimiento introdujo nuevos cambios en el modo de entender el proceso de traducción. En España la revalorización del español frente al latín como lengua del Imperio gracias al reinado de Carlos V significó para la lírica española la apertura a nuevas formas de componer poesía, pues las relaciones hispano-italianas supusieron además para las letras españolas la introducción del movimiento llamado petrarquismo. Las traducciones españolas de autores italianos como Petrarca ayudaron a la adaptación y asimilación del nuevo estilo importado desde la Península Itálica. Concretamente, la traducción de Hernando de Hozes de los Triumphi supuso para la creación literaria una importante influencia pues contribuyó a la consolidación y al enriquecimiento del movimiento petrarquista en la lírica castellana, así como a la asimilación de los nuevos conceptos de traducción en el Renacimiento.

PALABRAS CLAVE: lírica castellana, proceso de traducción, siglo XVI, Renacimiento, Triumphi.

\title{
Filosofía del Renacimiento en la traducción de Hernando de Hozes
}

Alicia M. a López MÁrouez

Universidad Pablo de Olavide de Sevilla

\section{Renaissance Philosophy in the Translation of Hernando de Hozes}

The Renaissance led to changes in the way people understood the process of translation. In the Spanish Empire of Charles $v$, Spanish started to replace Latin and the translation of Italian poetry - notably Petrarch - into Spanish led to the blossoming of Petrarchism in Spanish literature. Hernando Hoze's translation of the Triumphi played a particularly important role both in propagating Petrarchism in the peninsula and in contributing to changes in the translation process.

KEY WORDS: Spanish poetry, translation process, 16th Century, Renaissance, Triumphi. 


\section{INTRODUCCIÓN}

En el siglo XVI las relaciones entre España e Italia se intensificaron gracias a la expansión política y militar llevada a cabo por Carlos v, originando un recíproco intercambio cultural, fruto de los continuos desplazamientos humanos y de la circulación de libros entre ambos países.

Concretamente, en el campo de la literatura la influencia italiana marcó un antes y un después en el desarrollo de la poesía española, gracias a la temprana adopción de los nuevos cánones literarios italianos por parte de los escritores españoles (Lefèvre, 2006: Io).

Así, no podemos olvidar que el encuentro que tuvo lugar en 1526 en Granada entre Juan Boscán, poeta y traductor, y el embajador Andrea Navagero, escritor y diplomático italiano en la corte de Carlos v fue decisivo e indicio de lo que posteriormente sucedería, es decir, la implantación de las formas métricas italianas.

Otra de las cuestiones importantes de esta época fue la revalorización del español como lengua universal. Recordemos que el mismo Carlos v, en 1536 en la Corte Pontificia en Roma, proclamó la lengua española como «común de la Cristiandad, lengua oficial de la diplomacia» ${ }^{\mathrm{r}}$. De hecho, en los años treinta (entre 1535 y I536) aparece la famosa obra de Juan Valdés, Diálogo de la lengua, en la que se planteaban cuestiones importantes como por ejemplo:

La relación de las lenguas vulgares con el latín, los usos hablados y escritos del castellano, el problema de ausencia de autoridades [...] y, naturalmente, las dificultades de la traducción en unos tiempos en los que casi todo estaba por hacer, especialmente en la lengua castellana (Micó, 2004: 176).

I Citado en Gauger (2004: 45).
Por lo tanto, es una época de importantes cambios para las lenguas vulgares, en concreto para el español y para la traducción. Además, debemos tener en cuenta que en el siglo XVI tiene lugar la primera y gran revolución en el mundo de la traducción y que muchas de las traducciones del latín al castellano fomentaron el conocimiento de grandes clásicos que renacieron con el Humanismo. De hecho, según Hurtado (2001: 107):

Hechos como el descubrimiento de la imprenta, el surgimiento de una nueva clase de lectores, el nacimiento de las lenguas nacionales, el papel de la traducción como agente transportador de la cultura de la Antigüedad, multiplican y varían los textos traducidos.

\section{ALGUNOS ASPECTOS FUNDAMENTALES DE LA TRADUCCIÓN EN EL RENACIMIENTO}

En relación con la traducción, según Recio (2005: 2 y ss.), el cambio de mentalidad se hace manifiesto desde el siglo XIV, cuando se empieza a considerar la posibilidad de traducir en lenguas vernáculas para, de este modo, abandonar la imposición del latín sobre otras lenguas romances, aunque siguieran existiendo escritores que condenaran sin reservas las traducciones del latín a este tipo de lenguas.

Si nos fijamos en el siglo xv, en España se prefiere una prosa más alejada del latín. En general, como señala Russel (I985: 22), se traduce para que un lector sin conocimientos de la lengua latina pueda entender sin problemas la versión realizada.

Para ello, Russel (1985: 27) recuerda la teoría de la traducción instaurada por San Jerónimo desde la Edad Media hasta el Humanismo en la que «el verdadero traductor es aquél que intenta 
captar en su propia lengua el significado total del texto original, traduciendo las ideas de este último y no las palabras exactas», pues, según San Jerónimo, cada lengua tiene «su genio»y es necesario que el traductor lo respete y tenga en cuenta.

Como indica Micó (2004: I75), los traductores del Renacimiento (y con posterioridad los del Barroco) tuvieron la difícil tarea de poner en práctica y transmitir las ideas y también los ideales que habían surgido en los debates un siglo antes. Micó hace referencia a los grandes debates humanistas que, por ejemplo, mantuvieron Leonardo Bruni y Alonso de Cartagena, aunque ya en el XVI las cuestiones que se tratan van más allá de la restauración del mundo clásico, pues ahora surgen otras preocupaciones y ocupaciones como el crecimiento de los lectores o las traducciones en lenguas vernáculas de las Sagradas Escrituras, así como el descubrimiento de un nuevo continente con sus nuevos objetos y nuevas palabras que no se conocían en la vieja Europa y que había que interpretar en otras lenguas. Asimismo, el pensamiento humanista instaura la práctica, entre otras, del prólogo, del prefacio, de la carta dirigida a los lectores, donde se explican y justifican sus opciones de traducción. Dichas prácticas «constituyen un corpus traductológico de primer orden» (Hurtado Albir, 2004: 107), y sirven para entender y explicar muchas de las opciones adoptadas por algunos traductores en épocas pasadas.

Una mención aparte merece la traducción castellana de Juan Boscán de Il Cortigiano, en la que se ponen de manifiesto, según gran parte de la crítica, ${ }^{2}$ muchos de los cambios que se estaban llevando a cabo en cuanto a la nueva forma de concebir el proceso de traducción. En ella el

\footnotetext{
2 Como, por ejemplo, Fernández Murga (I989), Lapesa (I980), Terracini (1996) y Reyes Cano (1984).
}

propio Boscán ${ }^{3}$ diferencia entre «romanzar», tan criticado por él: «opinión que siempre tuve de parecerme vanidad baxa y de hombres de pocas letras andar romanzando libros» $\mathrm{y}$ «traducir», ya que aclara que su versión en castellano de $\mathrm{Il}$ Cortigiano «no es propiamente romanzalle, sino mudalle de una lengua vulgar en otra quizá tan buena». Garcilaso ${ }^{4}$ fue el primero que se dio cuenta del valor de dicha traducción catalogándola como:

Una traducción distinta y excepcional confrontada con los criterios que hasta el momento regían en las versiones españolas de textos extranjeros. Vio en ella el poeta toledano no la estrecha fidelidad del que se ata al rigor de la letra, sino la honda del que sigue sobre todo la verdad de las sentencias (Reyes Cano, 2009: 58).

Según Lore Terracini (r996: 940), uno de los conceptos primordiales de la traducción de Boscán y que prevalecerá en el siglo XVI es, sobre todo, el carácter comunicativo, es decir, que otros entiendan lo que se ha escrito en una lengua diferente a la propia. Destaca la autora que este motivo didascálico en España se remonta a Alfonso el Sabio, continúa con las traducciones medievales y del siglo xv y se extiende hasta muy avanzado el siglo XVI. Dos de los aspectos que resalta Terracini (I996: 940) y que va en consonancia con la actitud «típicamente renacentista» son, por un lado, el cariño hacia la propia lengua y así destaca las palabras de Garcilaso: «tengo por muy principal el beneficio que se hace a la lengua castellana en poner en ella cosas que merezcan ser leídas»y, por otro, «la conciencia

3 Cit. en Micó (2004: I77-178).

4 El propio Garcilaso fue quien aconsejó a Boscán que tradujera dicha obra.

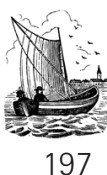

197 
de peculiaridad de cada idioma». De esta forma, existe ya en la primera mitad del siglo XVI una conciencia traductora y lingüística que:
Va más allá [...] de los aspectos terminológicos, la reflexión española sobre la traducción [...] está intrínsecamente vinculada con la reflexión sobre la misma lengua, en todas sus facetas renacentistas y sobre todo en la valoración de su plena dignidad frente a las lenguas hermanas e incluso a las lenguas clásicas [... (Terracini, 1996: 943).

Hasta aquí hemos expuesto algunos de los cambios más relevantes que surgieron en el Renacimiento en el proceso de la traducción, tomando como modelo algunas particularidades de la traducción de Boscán. A modo de conclusión, podemos añadir que el crecimiento de la traducción en esta época fue verdaderamente asombroso y, en lo que se refiere a la Península Ibérica, el siglo XVI supone un florecimiento, en particular, de traducciones de los escritores italianos más famosos entre los que destacamos Dante, Petrarca y Boccaccio.

\section{LA TRADUCCIÓN DE HERNANDO DE HOZES (I554): ASPECTOS RENACENTISTAS}

En relación con la traducción y en concreto con la literaria, como subraya Micó (2004: I84), los casos más importantes e interesantes tienen que ver con la poesía, ya que, además de la interpretación y la equivalencia de estilos, hay que contar con la adaptación formal. De este modo, prosigue Micó, «el traductor está más cerca que nunca de la posibilidad de enfrentarse a un desafío verdaderamente literario y a la necesidad de afinar su conciencia creativa».

Un caso de adaptación formal y de contenido lo encontramos en la versión castellana de los Triumphi de Petrarca realizada por Hernando de Hozes a mitad del siglo XVI, donde ya desde su prólogo dedicado a don Juan de la Cerda, duque de Medinaceli, el traductor invita a los lectores a leer los Triunfos de la misma manera en que habían sido concebidos por el poeta italiano, es decir, con la métrica y el ritmo originales, en vez de la tradición del metro octosilábico de la poesía cancioneril por la que se regían las versiones anteriores: la parcial de Alvar Gómez (I510?) y la de Antonio de Obregón (I512), que tradujo la obra completa. Aunque el mismo Hozes (1554: fol. 2) elogia en su prólogo la traducción de Obregón («a mi parescer de las mejores»), justifica su nueva e innovadora versión con el hecho de que algunos amigos suyos no entendían el toscano y que no por ello podía consentir que se privaran de conocer tal magnífica obra, en la misma forma en que la creó Petrarca: «[...] porque algunos amigos mios que no entendían el Thoscano, no dexassen por esta causa de ver una cosa de tanto valor como los Triumphos».

Con ello, además, se comprometía a cumplir los preceptos métricos importados desde Italia: los versos debían terminar en vocal y no ser oxítonos, objetivos estos difíciles de salvar en nuestra lengua española pero que él llevó a cabo en su versión. Así, Hozes señala otro de los aspectos renacentistas, esta vez en el apartado titulado Al lector, es decir, la peculiaridad de la lengua castellana, pues en algunos estadios de la traducción ha tenido que apartarse más de lo debido del original italiano, para que así se pudiera cumplir con los dos preceptos mencionados, y no ir en contra de «la opinión de tantos, como los que el dia de oy son de voto, que al pie de la letra, se imite también enesto la manera del verso italiano, como en todas las otras cosas [...]» (Hozes, 1554: fol. Ir). A modo de ejemplo, podemos citar el terceto que hace referencia al general y político romano, Quin- 
to Cecilio Metelo, llamado «El Feliz», (TF I5, vv. II5-II7) donde el traductor reduce la unión de dos adjetivos por coordinación copulativa:

E quel che parve altrui beato e lieto; non dico fu, ché non chiaro si vede un chiuso cor in suo alto secreto:

en un solo adjetivo para cumplir con el metro y la rima:

$\mathrm{Y}$ aquel que muchos llaman en efecto alegre, y no lo sé, pues no parece claro lo que en el alma está secreto.

De esta manera, Hozes es consciente de que su tarea de tomar del original la métrica y el ritmo dificulta en gran medida su proceso de traducción, disculpándose de todo aquello que ha tenido que sacrificar para no alejarse del sentido del texto de partida.

Este concepto del que ya hemos hablado, sobre la peculiaridad de la lengua y la dificultad de la traducción, según Terracini (ig96: 947) llega a través de Quintiliano y San Jerónimo y en Italia aparece con Leonardo Bruni y más tarde con Bembo. Ya en España, subraya la autora, esta característica la podemos apreciar en Alfonso de Cartagena y en Alfonso de Madrigal el Tostado, «en la estela de San Jerónimo» («la condición propia de la fabla de cada lengua»).

Hozes no solo aplicará a su nueva versión la misma métrica del original italiano, sino que también modifica la glosa que acompaña la última traducción completa de Obregón, es decir, mientras que este último seguía en su comentario a Illicinio, Hozes componía su glosa principalmente con la adaptación de la glosa de Vellutello, otro de los importantes comentaristas de Petrarca que se puso de moda a partir de

5 Triunfo de la Fama la mitad del siglo xv, puesto que la autoridad del comentario de Illicinio $^{6}$ se había perdido para entonces (Recio, 2000: 1512):

$\mathrm{Y}$ assi mismo le puse nuevo commento, no tan breve como el de Alessandro Vellutello, ni tan largo en muchas cosas, como el de Bernardo Illicinio, sino tomando a pedaços de entrambos, quitando algo de lo que parecia superfluo y añadiendo lo que en mi juizio era muy neccesario (Hozes, 1554: fol. 2).

\section{MOdULACión DEL CONTEXTO EXTRALINGÜÍSTICO}

En el caso que exponemos a continuación se puede apreciar cómo Hozes adapta en su comentario y, por ende, en su traducción la descripción de uno de los personajes citados por Petrarca. Nos encontramos en el segundo capítulo del TF. El poeta presenta a los héroes del ciclo troyano, como, por ejemplo, a Aquiles, héroe de la guerra de Troya; a los atenienses exiliados, Teseo y Arístides, entre otros; y a algunos personajes bíblicos, como son los patriarcas Isaac y Jacob.

$\mathrm{El}$ pasaje que presentamos hace referencia a las figuras de dos guerreros: Hierón, señor de Siracusa en Sicilia, y Almílcar Barca, general de los cartagineses, llamado el «cruel» por haber educado a su hijo, el famoso Aníbal, en el odio hacia los romanos. Relata Petrarca:

Con lui, mirando quinci e quindi fiso, Iero siracusan conobbi, e ' 1 crudo Amilcare da lor molto diviso.

Y Hozes traduce:

Mirando más la gente que pasaba

6 Obregón tradujo el comentario de Illicinio en su versión de I512.

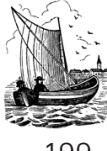

199 
Hierón siracusano vi, y el cuerdo

Almílcar, que de entrambos se apartaba.

Destacamos en este pasaje la traducción del calificativo del personaje de Almílcar:

Iero siracusan [...] e 'l crudo Amilcare à 'Hierón siracusano [...], y el cuerdo Almílcar' Crudo a 'cuerdo'

Mientras el poeta italiano le confiere el sobrenombre de crudo, por el que era conocido por su odio hacia los romanos, como ya hemos comentado, y que más tarde inculcaría a Aníbal, uno de sus hijos, Hozes, en cambio, elige el apelativo de 'cuerdo', apartándose así del significado del calificativo italiano. Si nos ceñimos al relato de la vida del general que se expone en la glosa, llama la atención el trato amable que se le concede. De hecho, la historia de este empieza antes de su participación en la primera Guerra Púnica contra los romanos (Pacca, I996: 406), con la llegada a España, ${ }^{7}$ mandado por el ejercito cartaginés para apaciguar los ánimos en la isla de Mallorca en el 248 a. C.

$\mathrm{Al}$ respecto, Hozes (ibídem., fols. I4OV-I42v) narra que, lejos de someter a los isleños, como así le habían mandado, no solo se ganó la confianza de estos «con clemencia y benignidad», sino también la de los «muchos pueblos de España de las riberas cercanas a la dicha ysla, [...], Cataluña y reyno de Valencia» y además para estrechar aún más los lazos «se casó con una señora de nuestra nación, cuyo nombre ni linage no se dice». Sigue el traductor elogiando a Almílcar, esta vez para advertir de la suerte de su esposa «pues hombre de tanto valor y calidad como Hamílcar se casava con ella».

Por lo tanto, es evidente que el traductor

7 Según Wagner (I999: 265), un año más tarde, en el 237 a. C. desembarca en Gadir para llevar a cabo la conquista de algunos territorios peninsulares. ha querido ensalzar la vida de este general, sobre todo por sus incursiones en la Península Ibérica, asignándole un adjetivo que, sin rozar la admiración, difiere del calificativo utilizado por el poeta italiano. Con este procedimiento modula a su antojo la realidad extralingüística del original. De hecho, al inicio de este mismo capítulo, Hozes ( 1554, fols. II7r-II8v) introduce en la glosa una larga digresión en la que se lamenta del poco espacio que en los Triumphi ocupan los héroes de la Península Ibérica. Asimismo justifica este hecho con la poca difusión que se ha dado a las hazañas españolas, ya que la falta de cronistas españoles ha dificultado que el mismo Petrarca pudiera tener noticias de ellas. Así pues, Hozes recrea para el público el comentario de su traducción y en consecuencia la descripción del personaje en sus versos, resaltando una de las hazañas históricas llevadas a cabo por este general en España.

Hoy en día este proceso de manipulación del contexto histórico sería casi impensable, pero para la época podríamos decir que era una práctica habitual, como por ejemplo hiciera Jerónimo de Urrea en su traducción del Orlando furioso de Ariosto de 1548, en la que «eliminó buena parte del canto tercero (el de la exaltación de la familia d'Este) [...]» y «dulcificó las críticas ocasionales a los españoles» (Micó, ibídem, 93).

En conclusión, la traducción de Hozes, además de contribuir a la introducción y consolidación de la nueva forma de componer poesía que llegaba desde Italia y poner de manifiesto la importancia de un modo de petrarquismo muy usado y conocido por muchos poetas españoles de la época (Garcilaso de la Vega, Fernando de Herrera...), significó la asimilación de algunas de las ideas renacentistas sobre el proceso de traducción. Al mismo tiempo, el propio traductor fue muy consciente, por ejemplo, de la peculiaridad de la lengua española frente a la lengua 
italiana, subrayando de la primera, (como ya lo hiciera San Jerónimo, respecto a todas las lenguas) «su genio» y buscando las equivalencias apropiadas de nuestra lengua y cultura, tanto desde el punto de vista formal como desde el punto de vista del contenido. ${ }^{8}$

RECIBIDO EN SEPTIEMBRE DE 2012 ACEPTADO EN NOVIEMBRE DE 2012 VERSIÓN FINAL DE ENERO DE 2OI3

\section{REFERENCIAS BIBLIOGRÁFICAS}

Castiglione, B. (1984). El Cortesano. Trad. de Juan Boscán, introd. y notas de Rogelio Reyes Cano. Madrid: Espasa Calpe.

Fernández Murga, F. (1989). «La traducción de autores italianos», en Actas del VI Simposio de la Sociedad de Literatura General y Comparada. Granada I3-I5 marzo 1986. Granada: Universidad de Granada, pp. 313-320.

Gauger, H. (I989). «La conciencia lingüística en el Siglo de Oro", en Actas del IX Congreso de la Asociación Internacional de Hispanistas, I8-23 agosto I986, coord. Sebastián Neumeister, vol. I, Vervuert: Verlagsgesellschaft, pp. $45^{-64}$.

Hozes (de), H. (1554). Los Triumphos de Francisco Petrarcha, ahora nuevamente traduzidos en lengua Castellana en la medida y numero de versos que tienen en el Toscano. Medina del Campo: Guillermo de Millis.

Hurtado Albir, A. (200I). Traducción y traductología. Introducción a la traductologia. Madrid: Cátedra.

Lapesa, R. (1995). Historia de la lengua española. Madrid: Gredos.

Lefèvre, M. (2006). Una poesia per l'Impero. Roma: Vecchiarelli Editore.

López Márquez, A. M. (2006). «El endecasílabo en la traducción. Experiencia castellana de Her-

8 Para más información sobre las técnicas utilizadas por Hozes en su versión, véanse: López Márquez (2006, 20ro) y López Márquez y Flores Acuña (2007). nando de Hozes». En Investigación en traducción e interpretación. Una mirada al presente, Encarnación Postigo (coord.), Málaga: Universidad de Málaga, pp. 499-518.

- (2010). «Las estrategias de la modulación y de la transposición en la traducción de Hernando de Hozes (I554)», Revista literaria Katharsis: <www. revistakatharsis.org/estrategias_de_la_modulacion.pdf> [Consulta 22-II-20I2].

López Márquez, A. M., y Estefanía Flores Acuña, (2007). «Los Triumphi de Petrarca: breve estudio lexicográfico de los adjetivos dedicados a Laura en la traducción de Hernando de Hozes». En Perfiles para la historia y critica de la lexicografía bilingüe del español. Felix San Vicente (ed.), Milán: Polimetrica, pp. 292-306.

Micó, J. M. ${ }^{a}$ (2004). «La época del Renacimiento y del Barroco». En Francisco Lafarga y Luis Pegenaute (eds.). Historia de la traducción en España. Salamanca: Ambos Mundos, pp. 1515-1533.

Pacca, V., y L. Paolino (1996). Trionfi. Rime estravaganti, Codice degli abbozzi. Milán: Mondadori.

Recio, R. (2005). «La traducción en las coronas de Aragón y Castilla». En Biblioteca virtual E-Excellence <http://www.liceus.com/cgi-bin/ aco/lit/o4/oroo.asp> [Consulta Io-Io-20II].

- (2000). «El nuevo petrarquismo y el petrarquismo cuatrocentista. Hozes y los otros traductores castellanos de los Trionfi». En Actas del viII Congreso Internacional de la Asociación Hispánica de Literatura Medieval, 1999. Santander: Universidad Internacional Menéndez Pelayo, pp.I523-I534.

Russell, P. (1985). Traducciones y traductores en la Peninsula Ibérica (I400-I550), Barcelona: Servicio de publicaciones de la Universidad Autónoma de Barcelona.

Terracini, L. (1996). «Unas calas en el concepto de traducción en el Siglo de Oro». En A. Alonso González (coord.), Actas del III Congreso Internacional de Historia de la Lengua española, Salamanca 22-27 noviembre 1993, vol. r, Madrid: Arco-libros, pp. 939-954.

Wagner, C. G. (I999). «Los Bárquidas y la conquista de la PenínsulaIbérica». En Gerión r7. Servicios de publicaciones de la Universidad Complutense de Madrid: Madrid.

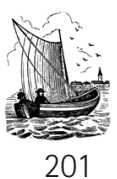

